\title{
ANALISIS TATANIAGA KOPI ARABICA (COFFEA ARABICA L) DESA MEREK, KECAMATAN MEREK, KABUPATEN KAROSUMATERA UTARA TAHUN 2019
}

\author{
Oleh: \\ Dippu Pasaribu ${ }^{1)}$ \\ Robert G. Marpaung ${ }^{2)}$ \\ Jenni A Mendrofa ${ }^{3)}$ \\ Universitas Darma Agung,Medan ${ }^{1,2,3)}$ \\ E-mail: \\ tigorjonatan@gmail.com ${ }^{1)}$ \\ $\frac{\text { robert.marpaung2012@gmail.com }}{\text { jenianggrenimed4@gmail.com }^{3)}}$
}

\begin{abstract}
This study aims at determining the channels, functions and institutions of the Arabica coffee trading system in the research area, the margin of the trading system produced by the Arabica coffee (coffeaarabica L) in the study area, the efficiency level of the Arabica coffee trading system (Coffeaarabika. in the research area. The research area was determined by purposive sampling in Brand Village, Merek District, Karo Regency which was held in May 2019 - August 2019. The sampling method was carried out by simple random sampling (simple random). The samples in this study are farmers who cultivated Arabica coffee throughout the year. The number of samples in this study was 30 samples and the sample of traders was determined by the tracing method, namely tracing all traders involved in the Arabica coffee trading process. There are two marketing channels for Arabica coffee in the research area, namely farmers - collecting traders - subdistrict traders and subdistrict farmers - traders. The marketing margin for Arabica coffee from farmers to consumers on channel I is Rp. 14,500, on channel II is Rp. 14,300. The coffee marketing channels in Brand Village, Brand District, Karo Regency are efficient. Of the two marketing channels, the most efficient marketing channel compared to other marketing channels is the second marketing channel, namely sub-district farmers - traders.
\end{abstract}

Keywords: Commerce, Arabica Coffee, Marketing Margin

\begin{abstract}
ABSTRAK
Penelitian ini bertujuan untuk mengetahui saluran, fungsi dan lembaga tata niaga kopi Arabica di tempat penelitian, (2) margin tataniaga yang dihasilkan tataniaga kopi arabika (coffeaarabica L) di daerah penelitian, (3) tingkat efesiensi tataniaga kopi arabika (Coffeaarabika .L) di daerah penelitian. Daerah penelitian ditentukan secara purposive sampling di Desa Merek, Kecamatan Merek, Kabupaten Karo yang dilaksanakan pada bulan Mei 2019 - Agustus 2019. Metode penarikan sampel dilakukan dengan cara Simple random sampling (acak sederhana). Sampel dalam penelitian ini adalah petani yang mengusahakan tanaman Kopi Arabika sepanjang tahun. Jumlah sampel pada penelitian ini sebesar 30 sampel dan sampel pedagang ditentukan dengan metode penelusuran yaitu menelusuri semua pedagang yang terlibat dalam proses tataniaga kopi Arabika. Ada dua saluran pemasaran kopi Arabika di daerah penelitian yaitu petani - pedagang pengumpul - pedagang Kecamatan dan petani - pedagang Kecamatan. Margin pemasaran kopi Arabika dari petani sampai ke konsumen pada
\end{abstract}


saluaran I sebesar Rp.14.500, pada saluran II sebesar Rp.14.300. Saluran pemasaran kopi di Desa Merek, Kecamatan Merek, Kabupaten Karo sudah efisien. Dari kedua saluran pemasaran tersebut, saluran pemasaran yang paling efisien dibandingkan dengan saluran pemasaran lainnya adalah saluran pemasaran kedua yaitu petani - pedagang kecamatan.

\section{Kata kunci: Tataniaga, Kopi Arabica, Margin Pemasaran}

\section{PENDAHULUAN}

\section{Latar Belakang}

Sebagai salah satu negara sedang berkembang, Indonesia memiliki banyak karakteristik dan potensi sumber daya pembangunan yang banyak bertumpuk pada sector pertanian, oleh sebab itu negara Indonesia di sebut juga sebagai negara agraris yang mata pencahariannya dominan dalam pertanian.

Kopi Arabica adalah kopi tradisional dan di anggap paling enak rasanya. Kopi yang berasal dari Etiopia ini sekarang sudah di budidayakan di Indonesia. Dengan ciri-ciri memiliki variasi rasa yang lebih beragam,dari rasa manis dan lembut dan halus hingga kuat dan tajam. Kopi Arabica menguasai 70 persen pasar kopi dunia dan memiliki banyak varietas, tergantung negara,iklim,dan tanah tempat kopi di tanam (Budiman, 2010)

Negara Indonesia menjadi salah satu penghasil kopi terbaik di dunia dan sebagai penghasil kopi Arabica terbaik ke dua di dunia setelah Vietnam.Total Produksi kopi Indonesia mencapai 700.000 ton per tahun.Dari jumlah tersebut 80\% kopi Arabika dan 90\% kopi Arabica di ekspor. Kopi Arabica yang telah di kenal di dunia Antara lain kopi Gayo, Kopi Sumatera, kopi Jawa dari jawa timur, Bali dan Flores.

Table 1. Luas Panen dan Produksi Kopi Arabica (Coffea Arabica L.)Menurut Provinsi Tahun 2017

\begin{tabular}{|l|l|c|c|}
\hline No & Provinsi & Luas Panen (Ha) & Produksi (ton) \\
\hline 1. & Aceh & 100.422 & 63.709 \\
\hline $\mathbf{2 .}$ & Sumatera Utara & $\mathbf{6 2 . 9 8 5}$ & $\mathbf{5 4 . 0 7 3}$ \\
\hline 3. & Sumatera barat & 16.209 & 10.669 \\
\hline 4. & Jambi & 1.320 & 190 \\
\hline 5. & Bengkulu & 4.024 & 1.329 \\
\hline 6. & Lampung & 66 & 40 \\
\hline 7. & Jawa barat & 19.900 & 9.227 \\
\hline 8. & Jawa tengah & 6.408 & 1.680 \\
\hline 9 & D.I. Yogyakarta & 50 & 13 \\
\hline 10. & Jawa timur & 14.638 & 5.270 \\
\hline 11. & Bali & 12.377 & 3.654 \\
\hline 12. & Nusa tenggara barat & 3.644 & 628 \\
\hline 13. & Nusa tenggara timur & 19.496 & 6.692 \\
\hline 14. & Sulawesi utara & 277 & 117 \\
\hline 15. & Sulawesi tengah & 205 & 49 \\
\hline 16. & Sulawesi selatan & 48.658 & 19.012 \\
\hline 17. & Sulawesi barat & 6.238 & 1.039 \\
\hline 18. & Papua & 10.448 & 2.009 \\
\hline 19. & Papua barat & 514 & 114 \\
\hline & Total & $\mathbf{3 2 7 . 8 8 8}$ & $\mathbf{1 7 9 . 5 1 3}$ \\
\hline
\end{tabular}

Sumber : Direktoral Jendral Perkebunan Tahun 2018 
Dari tabel di atas dapat di ketahui bahwa provinsi Sumatera Utara merupakan penghasil kopi Arabica terbesar nomor dua di sumatera utara dengan luas areal $62.985 \mathrm{Ha}$, dan produksi 54.073 ton setelah Provinsi Aceh dan memiliki produksi sebesar 54.073

Merek adalah salah satu desa yang berada di kecatan Merek kabupaten Karo Provinsi Sumatera Utara dan salah satu desa yang merupakan penghasil kopi Arabica, karena salah satu mata pencaharian di desa tersebut bergantung pada hasil pertaniannya (Bertani). Peningkatan pendapatan dapat di lakukan dengan memperhatikan sistem Tataniaga di Desa Merek di tersebut.

Berdasarkan uraian di tersebut penulis tertarik melaksanakan penelitian dengan judul " Analisis Tataniaga Kopi Arabica (CoffeaArabica L.)" di Merek kecamatan Merek kabupaten Karo Provinsi Sumatera Utara.

\section{Identifikasi Masalah}

Adapun yang menjadi permasalahan dalam penelitian adalah sebagai berikut:

1. Bagiamana saluran,fungsi dan lembaga Tataniaga Kopi Arabica (Coffea arabica L.) di daerah penelitian?

2. Bagaimana margin Tataniagayang di hasilkan tataniga kopi Arabica (Coffea Arabica L.) di daerah penelitian?

3. Bagaimana tingkat kelayakan usahatani kopi arabika (Coffea arabica L.) di daerah penelitian?

\section{Tujuan Penelitian}

1. Mengetahui saluran ,Fungsi dan lembaga tataniaga kopi Arabica di tempat penelitian.

2. Mengetahui margin tataniga yang dihasilkan tataniaga kopi arabika (coffea arabica L) didaerah
penelitian.

3. Untuk mengetahui tingkat efesiensi tataniaga kopi arabika (Coffea arabika .L) di daerah penetian

\section{TINJAUAN PUSTAKA}

\section{Aspek Ekonomis}

Tingkat konsumsi kopi dalam negeri berdasarkan hasil survey LPEM UI 1989 adalah sebesar 500 gram /kapita/tahun.Dewasa ini kalangan pengusaha kopi memperkirakan tingkat konsumsi kopi di Indonesia telah mencapai 800 gram /kapita/tahun. Dengan demikian dalam kurung waktu 20 tahun peningkatan konsumsi kopi telah mencapai 300 gram /kapita/tahun (Haryanto Budiman)

Peningkatan kebutuhan akan kopi menyebabkan meningkatnya permintaan akan kopi. Kebutuhan kopi sebagai sumber minuman penyegar telah berkembang pesat,dimana kopi di olah melalui beberapa proses tertentu,umtuk menghasilkan minuman dengan rasa khas.Berikut di sajikan kandungan apa saja yang terdapat dalam 100 gram kopi.

\section{Landasan Teori}

Petani sebagai orang dewasa yang bercocok tanam, artinya mereka bercocok tanam di daerah pedesaaan ,tidak dalam ruangan tertutup di tengah kota. Petani tidak melakukan usaha tani dalam arti ekonomi, ia mengelolah sebuah rumah tangga,bukan sebuah perusahaan bisnis ,namun demikian di katakan pula bahwa petani merupakan bagian dari masyarakat yang lebih luas dan besar (Periando, 2015)

Kegiatan produksi adalah mengkombinasikan berbagai sumber daya atau masukan untuk menghasilkan produksi atau output. Produksi 
merupakan kegiatan yang di ukur sebagai timgkat-tingkat output/unit periode atau waktu. Sedangkan outputnya sendiri senantiasa di asumsikan konstan kualitasnya

\section{(Miller dan Meiners)}

Tataniaga merupakan suatu istilah yang di artikan sama dengan pemasaran atau distribusi, yaitu sebagai kegiatan ekonomi yang memiliki fungsi untuk menyampaikan atau membawa barang maupun jasa dari produsen hingga konsumen. Sistem tataniaga di anggap efesien apabila memenuhi dua syarat, yaitu :

a. Mampu menyampaikan hasil-hasil dari petani produsen kepada konsumen dengan biaya semurahmurah nya

b. Mampu mengadakan pembagian yang adil dari keseluruhan harga yang di bayar konsumen akhir kepada semua pihak yang ikut serta di dalam kegiatan produksi tataniaga barang itu (Mubyarto, 2001)

Menurut (Kottler, 2009)

Tataniaga sebagai suatu aktivitas bisnis yang di dalamnya terdapat aliran barang dan jasa dari titik produksi sampai ke titik konsumen. Produksi adalah penciptaan kepuasan,proses membuat kegunaan barang dan jasa. Kepuasan di bentuk dari proses produktif yang di klasifikasikan menjadi kegunaan bentuk, tempat,waktu dan pemilikan .

Menurut Kotler (2002), saluran tataniaga adalah serangkian lembaga yang melakukan semua fungsi yang di gunakan untuk menyalurkan produk dan status ke pemilikannya dari produsen ke konsumen. Produsen memiliki peranan utama dalam mengasilkan barangbarang dan sering melakukan sebagian kegiatan pemasaran,sementara itu pedagang menyurkan komoditas daam waktu, tempat,bentuk yang diinginkan konsumen. Hal ini berarti bahwa saluran tataniaga yang berbeda akan memberikan keuntungan yang berbeda pula kepada masing-masing lembaga yang terlibat dalam kegiatan tataniaga tersebut.

Lembaga tataniaga merupakan segala usaha yang berkait dalam jaringan lalu lintas barang-barang di masyarakat, seperti hal nyajasa-jasa yang di tawarkan oleh agen-agen atau perusahaan pedagang, perbankan, perusahaaan pengepakan dan peti kemas, perusahaan angkutan, usaha pertanggungan atau asuransi dan lain sebagainya. Perusahaan dagang, perusahaan pengepakan, perusahaan angkutan, perusahaan asuransi, ke semuanya memegang peranan dalam menyampaikan produk-produk itu ke pasar (konsumen) dengan menjamin sampainya produk-produk itu ke konssumen (pasar) tanpa ada kerusakan -kerusakan di samping waktu penyampaian yang tepat (Kartaspoerta, 2002).

barang) yang di butuhkan untuk mendapatkan sejumlah kombinasi barang atau jasa. Perusahaan selalu menetapkan harga produknya dengan harapan produk tersebut laku terjual dan boleh memproleh laba yang maksimal. HansendanMowen (2001) mendefenisikan 'harga jual' adalah sumber moneter yang di bebankan oleh suatu unit usaha kepada pembeli atau pelanggan atas barang atau jasa ayang di jual di serahkan. MenurutMulyadi (2001) pada prinsip harga jual harus dapat menutupi biaya penuh di tambah dengan laba yang wajar.

Efesiensi tataniaga adalah maksimalinasi penggunaan rasio inputoutput, yaitu mengurangi biaya input tanpa mengurangi kepuasan konsumen terhadap barang atau jasa. Kemampuan menyampaikan hasil-hasil dari petani produsen ke konsumen dengan biaya 
yang semurah-murahnya dan mampu mengadakan peembagian yanag adil dari keseluruhan harga yang di bayar. Konsumen terakhir kepada semua pihak yang ikut serta, di dalam kegitan produksi dan tataniaga barang itu merupakan salah satu syarat yang harus di penuhi apabila ingin di anggap efesien dalam system tataniaga.

\section{Hipotesis Penelitian}

1. Terdapat saluran, fungsi dan lembaga yang terlibat pada tataniaga kopi arabica (Coffea arabica L.) didaerah penelitian.

2. Margin tataniaga yang dihasilkan Tataniaga kopi arabica (Coffea arabica L. ) relatif tinggi di daerah penelitian.

3. Tataniaga kopi arabica( Coffea arabica L.) sudah efesien di daerah penelitian.

\section{METODE PELAKSANAAN}

\section{Lokasi Penelitian}

Penelitian di laksanakan di desa Merek, kecamatan Merek, Kabupaten Karo, Provinsi Sumatera Utara yang di pilih secara sengaja (Purposive) karena di lokasi ini merupakan salah satu centra produksi kopi arabica.

\section{Teknik Pengumpulan Data}

Data yang di perlukan dalam penelitian ini adalah data primer dan data sekunder. Data primer di kumpulkan melalui wawancara secara langsung dengan petani dan lembaga tataniaga yanag terpilih sebagai sample berdasarkan daftar pertanyaaan yang telah di siapkan. Data primer yang di perlukan berupa data kuantitatif dan data kualitatif mengenai volume penjualan dan pembelian ,biaya.fungsi alur tataniaga. Sedangakan data sekunder berupa data perkembangana harga,berbagai literatur berkaitan dengan kopi arabica

\section{Metode Analisis Data \\ a. Hipotesis 1}

Metode analisis data yang di gunakan untuk menjawab hipotesis 1 , dan di uji dengan menggunakan analisis deskriptif,dengan mengamati saluran tataniaga,fungsi tataniaga serta lembaga tataniaga yang berperan di daerah penelitian.

\section{b.Hipotesis2}

Hipotesis 2 di uji dengan margin tataniaga yang menggunakan rumus sebagai berikut :

$\mathrm{Mji}=\mathrm{Psi}-\mathrm{Pbi}$

$\mathrm{Mji}=\mathrm{Bti}-\pi \mathrm{i}$

Sehingga margin pemasaran total adalah :

$\mathrm{Mji}=\sum \mathrm{Mji}$

Menghitung share margin

$\mathrm{Sm}=\frac{\rho p}{p k} \times 100 \%$

Keterangan :

Mji = Margin pada lembaga ke-i

Psi = Biaya penjualan paa lembaga pemasaran

$\mathrm{Pbi}=$ Harga pembelian lembaga pemasaran ke-i

$\pi \mathrm{i}=$ Keuntungan lembaga

pemasaran ke-i

Bti = Biaya pemasaran lembaga pemasaran tingkat-I (produsen)

$\mathrm{Mji}=$ Margin pada lembaga tingkat $-\mathrm{i}$

$\mathrm{Mj} \quad=$ Margin pemasaran total

$\mathrm{Sm}=$ Share Margin

$\rho p \quad=$ Harga yang di terima dari pedagang

$\mathrm{Pk} \quad=$ Harga yang di bayar oleh konsumen akhir

Besarnya margin tataniaga,price spread yang berlaku sistematis dengan menggunakan rumus sebagai berikut :

$$
M=H k-H p
$$

Price spread dapat di hitung dengan :

$$
\mathrm{S}=\frac{H p}{H e}
$$

Keterangan $: \mathrm{S}=$ Price Spread 
Hp = Harga dari petani

$\mathrm{He}=$ Harga eceran

Marketing margin dapat di hitung dengan :

$\mathrm{MM}=\mathrm{Pr}-\mathrm{Pf}$

Keterangan :

$\mathrm{MM}=$ Marketing Margin

$\operatorname{Pr}=$ Harga di tingkat pedagang

eceran

Pf = Harga di tingakat petani

Rasio keuntungan terhadap biaya (\%)

$$
\frac{\mathrm{Li}}{\mathrm{Ci}} \times 100 \%
$$

Dimana :

$\mathrm{Li}=$ keuntungan lembaga ke-i

$\mathrm{Ci}=$ biaya lembaga $\mathrm{ke}-\mathrm{i}$

\section{c.Hipotesis 3}

Hipotesis 3 di uji dengan share

harga yang di terima petani

menggunakan formulasi sebagai

berikut :

$\mathrm{SF}=\frac{\mathrm{PF}}{\mathrm{PR}} \mathrm{x} 100 \%$

Dimana :

$\mathrm{SF}=$ Bagian yang di terima petani

$\mathrm{PF}=$ Harga di tingkat petani $(\mathrm{Rp} / \mathrm{kg})$

$\mathrm{PR}=$ Harga di tingkat konsumen $(\mathrm{Rp} / \mathrm{kg})$
Apabila share keuntungan dan margin tataniaga pada setiap lembaga tataniaga yang terlibat semakin merata dan lebih kecil dari 50\%.maka tataniaga di katakan efesiensi (Nazaria dan Wedastra dalam Ananda, 2009 )

\section{HASIL DAN PEMBAHASAN}

\section{TataniagaKopi Arabikadi Daerah Penelitian}

Saluran tataniaga merupakan aliran barang mulai dari produsen ke konsumen yang terjadi karena adanya lembaga tataniaga, perpindahan barang antar lembaga menimbulkan biaya oleh karena adanya biaya tataniaga maka timbulah perbedaan harga yang diterima oleh produsen dengan harga yang dibayarkan oleh konsumen yang disebut marjin tataniaga.Semakin pendek tataniaga maka semakin efisien sistem tataniaga.Hasil penelitian menunjukkan bahwa ada 2 (dua) saluran tataniaga kopi arabika di Desa Merek, Kecamatan Merek, Kabupaten Karo.

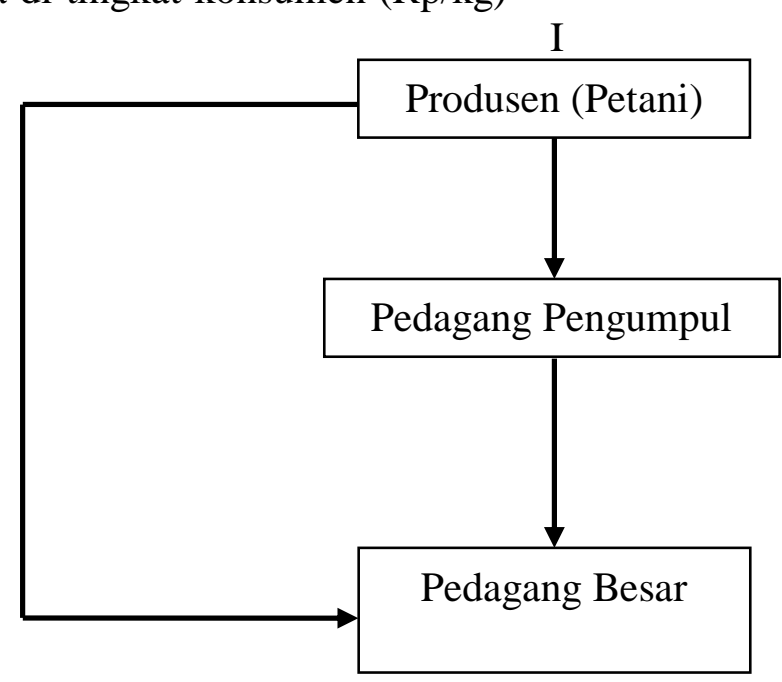

Gambar : Saluran Tataniaga Kopi Arabika di Desa Merek

Skema saluran tataniaga yang terlihat pada Gambar diatas merupakan skema saluran tataniaga yang terjadi pada kegiatan pemasaran kopi arabika yang dilakukanoleh pelaku pemasaran.Dalam penelitian ini, cakupan pelaku pemasaran yang diteliti adalah pelaku pemasaran yang berada di lingkungan daerah penelitian.Pada saluran satu (gambar 2) melibatkan petani kopi, pedagang pengumpul pedagang besar dan konsumen.Jenis 
saluran ini tidak banyak dilakukan oleh petani, karena keterbatasan petani terhadap mesin pengupas kopi yang mahal dan biaya pasca panen yang besar seperti pengemasan, transportasi, penjemuran, penyortiran, serta pengupasan kopi menjadi kopi gabah dan asalan, sehingga petani kopi di Desa Merek dominan menjual kopi glondong ke pedagang pengumpul dengan harga yang ditetapkan oleh pedagang pengumpul yaitu sebesar Rp.30.000/kg. Kemudian pedagang pengumpul menjual biji kopike pedagang besar setelah di sortir dan dijemur dengan harga Rp. $32.000 / \mathrm{kg}$.Kemudian pedagang besar mengolah biji kopi menjadi kopi asalan danpedagang besarmenjual kopi asalan dengan harga Rp.75.000/kg.

Saluran pemasaran II melibatkan petani dan pedagang besar.Jenis saluran pemasaran ini banyak dilakukan petani kopi di daerah penelitian.Jenis saluran pemasaran ini membutuhkan biaya pasca panen seperti penjemuran, penyimpanan, pengemasan, sortir dan transportasi. Harga jual petani ke pedagang besar dalam bentuk biji kopi yang sudah di sortir adalah sebesar Rp. $32.000 / \mathrm{kg}$ dan kemudian pedagang besar mengolah biji kopi menjadi kopi asalan siap ekspor dengan harga sebesar Rp.75.000/kg.

\section{Fungsi Tataniaga yang Dilakukan}

Setiap Saluran Tataniagadi

\section{Daerah Penelitian}

Dalam proses tataniaga kopi, fungsi-fungsi tataniaga yang

dilaksanakan oleh petani dan lembaga tataniaga bervariasai. Setiap lembaga tataniaga akan melakukan fungsi tataniaga mulai dari fungsi tataniaga hingga ke fungsi penjualan. Konsekuensi dari pelaksanaan fungsi ini adalah munculnya biaya-biaya satiap fungsi tataniaga.

Dengan demikian, hipotesis I yang menyatakan terdapat saluran, fungsi dan lembaga tataniaga yang terlibat pada tataniaga kopi arabika di daerah penelitian diterima.

\section{Margin Pemasaran, Price Spread, dan Share Margin pada Setiap Saluran Tataniagadi Daerah Penelitian}

Untuk menganalisis price spread dan share margin pemasaran maka perlu dihitung margin pemasaran yang dilakukan oleh masing-masing petani dan lembaga pemasaran. Marjin pemasaran pada saluran pemasaran kopi di daerah penelitian berbeda-beda besarnya karena adanya perbedaan biaya yang dikeluarkan untuk melakukan fungsi-fungsi pemasaran serta perbedaan harga jual yang ditetapkan. Efisiensi pemasaran penting untuk diketahui dengan tujuan untuk mengidentifikasi efisien atau tidaknya suatu saluran pemasaran.Efisiensi pemasaran dapat diketahui dengan menggunakan metode marjin pemasaran dan Farmer's Share. Berikut adalah tabel analisis biaya yang di keluarkan, keuntungan, marjin pemasaran dan Farmer's Share pada saluran pemasaran I:

Tabel 1: Komponen Margin, Price Spread(Rp/Kg), Share Margin(\%), Kopi Arabika per Kg Melalui Saluran I di Desa Merek, Kecamatan Merek, Kabupaten Karo, Tahun 2019

\begin{tabular}{|c|l|c|c|}
\hline No & \multicolumn{1}{|c|}{ Komponen Biaya } & $\begin{array}{c}\text { Price Spread } \\
(\mathbf{R p} / \mathbf{K g})\end{array}$ & $\begin{array}{c}\text { Share Margin } \\
(\boldsymbol{\%})\end{array}$ \\
\hline $\mathbf{1}$ & $\begin{array}{l}\text { Petani } \\
\text { - Harga Jual }\end{array}$ & 30.000 & 40 \\
\hline $\mathbf{2}$ & Pedagang Pengumpul & & \\
\hline
\end{tabular}




\begin{tabular}{|l|l|c|c|}
\hline & Harga beli & 30.000 & 40 \\
\hline & Harga Jual & 32.000 & 42,67 \\
\hline & Biaya Pemasaran & & \\
\hline & - Transportasi & 100 & 0,13 \\
\hline & - Tenaga Kerja & 100 & 0,13 \\
\hline & - Pengemasan & 100 & 0,13 \\
\hline & - Penjemuran & 100 & 0,13 \\
\hline & - Sortir & 100 & 0,13 \\
\hline & TotalBiaya & 500 & 0,67 \\
\hline & Provit & 1.500 & 2 \\
\hline & Marjin pemasaran & 2.000 & 2,67 \\
\hline $\mathbf{3}$ & Li/Ci & 3 & 0,00 \\
\hline & Pedagang Kecamatan & & \\
\hline & rga beli & 32.000 & 42,67 \\
\hline & Biaya Pemasaran & & \\
\hline & - Transportasi & 2.000 & 2 \\
\hline & - Penyusutan & 7.500 & 7,33 \\
\hline & - Biaya proses kopi & 4.000 & 4 \\
\hline & - Tenaga Kerja & 500 & 0,67 \\
\hline & TotalBiaya & 14.000 & 18,67 \\
\hline & Provit & 29.000 & 38,67 \\
\hline & Marjin Pemasaran & 43.000 & 57,33 \\
\hline & Li/Ci & 2,07 & 0,00 \\
\hline & Harga Jual & 75.000 & 100 \\
\hline
\end{tabular}

Berikut adalah tabel analisis biaya yang di keluarkan, keuntungan, marjin pemasaran dan Farmer's Share pada saluran pemasaran II:

Tabel 2 :Komponen Margin, Price Spread(Rp/Kg), Share Margin(\%), Kopi Arabika per Kg Melalui Saluran II di Desa Merek, Kecamatan Merek, Kabupaten Karo, Tahun 2019

\begin{tabular}{|l|l|c|c|}
\hline No & \multicolumn{1}{|c|}{ Komponen Biaya } & $\begin{array}{c}\text { Price Spread } \\
(\mathbf{R p} / \mathbf{K g})\end{array}$ & $\begin{array}{c}\text { Share Margin } \\
(\mathbf{\%})\end{array}$ \\
\hline $\mathbf{1}$ & Petani & & \\
\hline & Harga Jual & 32.000 & 42,67 \\
\hline & Biaya Produksi & 200 & 0,27 \\
\hline & Biaya Penjemuran & 50 & 0,67 \\
\hline & Biaya Transportasi & 50 & 0,67 \\
\hline & Total Biaya & 300 & 0,4 \\
\hline & Provit & 31.700 & 40,93 \\
\hline & Li/Ci & & 0,00 \\
\hline $\mathbf{2}$ & Pedagang Kecamatan & 32.000 & \\
\hline & Harga Beli & & 42,67 \\
\hline & Biaya Pemasaran & 2.000 & 2 \\
\hline & - Transportasi & 7.500 & 7,33 \\
\hline & - Penyusutan & & \\
\hline
\end{tabular}




\begin{tabular}{|l|l|c|c|}
\hline & - Biaya proses kopi & 4.000 & 4 \\
\hline & - Tenaga Kerja & 500 & 0,67 \\
\hline & Total Biaya & 14.000 & 18,66 \\
\hline & Provit & 29.000 & 38,67 \\
\hline & Marjin Pemasaran & 43.000 & 57,33 \\
\hline & Li/Ci & 1,48 & 0,00 \\
\hline & Harga Jual & 75.000 & 100 \\
\hline
\end{tabular}

\section{4.. Analisis Efesiensi Tataniaga}

Tujuan akhir yang ingin dicapai dalam proses pemasaran adalah efesiensi pemasaran yang dapat memberikan kepuasan kepada seluruh pelaku yang terlibat dalam pemasaran. Ukuran dari efesiensi adalah kepuasan dari konsumen atau petani, maupun lembaga-lembaga pemasaran yang terlibat didalam kegiatan mengalirkan produk dari petani sampai ke konsumen akhir. Nilai efesiensi pemasaran pada saluran pemasaran kopi arabika di daerah penelitian dapat dilihat pada Tabel 5.4

Tabel 3: Nilai Efesiensi Pemasaran (\%) pada Saluran Pemasaran Kopi Arabikadi Desa Merek, Kecamatan Merek, Kabupaten Karo, Tahun 2019

\begin{tabular}{|c|c|c|c|}
\hline Uraian & $\begin{array}{c}\text { Biaya } \\
(\mathbf{R p} / \mathbf{K g})\end{array}$ & $\begin{array}{c}\text { Harga di Tingkat } \\
\text { Konsumen } \\
(\mathbf{R p} / \mathbf{K g})\end{array}$ & $\begin{array}{c}\text { Efesiensi } \\
\text { Pemasaran }\end{array}$ \\
\hline Saluran Pemasaran 1 & 14.500 & 75.000 & 19,33 \\
\hline Saluran Pemasaran 2 & 14.300 & 75.000 & 19,06 \\
\hline
\end{tabular}

Pada Tabel 3 dapat dilihat bahwa nilai efisiensi dari semua lembaga pemasaran yang terlibat dalam pemasaran kopi di daerah penelitian adalah $<50 \%$, yang artinya saluran pemasaran di daerah penelitian sudah efisien. Dari kedua saluranpemasaran tersebut, saluran pemasaran yang paling efisien dibandingkan dengan saluran pemasaran lainnya adalah saluran pemasaran kedua yaitu petani pedagang besar karena dilihat dari efisiensi pemasaran pada saluran kedua yaitu $19,34 \%$ sedangkan pada saluran pertama nilai efisiensinya yaitu $19,34 \%$. Semakin kecil nilai efisiensi maka saluran pemasaran akan lebih efisien. Dengan demikian, hipotesis 3 yang menyatakan saluran tataniaga kopi di Desa Merek, Kecamatan Merek Kabupaten Karosudah efisien diterima karena hasil dari penelitian kedua saluran pemasaran kopi di daerah penelitian lebih kecil dari $50 \%$ yang artinya sudah efisien.

\section{SIMPULAN}

1. Ada dua saluran pemasaran kopi arabika di daerah penelitian yaitu petani - pedagang pengumpul pedagang kecamatan dan petani pedagang kecamatan.

2. Margin pemasaran kopi arabika dari petani sampai ke konsumen pada saluran I sebesar Rp.14.500, pada saluran II sebesar Rp.14.300.

3. Saluran pemasaran kopi di Desa Merek, Kecamatan Merek, Kabupaten Karo sudah efisien. Dari kedua saluran pemasaran tersebut, saluran pemasaran yangpaling efisien dibandingkan dengan saluran pemasaran lainnya adalah saluran 
pemasaran kedua yaitu petani pedagang kecamatan.

\section{DAFTAR PUSTAKA}

Ambarinanti, M. 2007. Analisis FaktorFaktor yang Mempengaruhi Produksi dan Kopi Indonesia.Skripsi.Fakultas Pertanian Institut Pertanian Bogor.

Badan Pusat Satistik (BPS). 2018. Luas Panen, Produksi, dan Produktivitas Kopi Arabika. Dalam Angka Tahun 2018. Jakarta Pusat. Badan Pusat Statistik.

Badan Pusat Statistik (BPS). 2018. Luas Panen, Produksi, dan Produktivitas Kopi Arabika per Kabupaten. Dalam Angka Tahun 2018. Sumatera Utara. Badan Pusat Statistik.

Badan Pusat Staistik (BPS). 2018. Luas Panen, Produksi, dan Produktivitas Kopi Arabika. Dalam Angka Tahun 2018. Kabupaten Karo. Badan Pusat Statistik.

Badan Pusat Statistik (BPS). 2018. Luas Penen, Produksi, dan Produktivitas Kopi Arabika. Dalam Angka Tahun 2018. Kecamatan Merek. Badan Pusat Statistik

Budiman, Haryanto. 2012. Prospek Tinggi Bertanam Kopi. Yogyakarta: Pustaka Baru Press.

Bishop, C.E., dan W.D. Toussaint. 2010. Pengantar Analisis Ekonomi Pertanian. Mutiara Sumber Widya. Jakarta.

Direktorat Jendral Perkebunan. Tahun 2017. Satisitik Perkebunan Produksi Kopi Arabika.

Firdaus, Y., 2007, Ekonomi dan Akuntansi, Jakarta: PT. Phibeta Aneka Guna.
Gaspersz, V. 2000. Manajemen Produktivitas Total,. Jakarta. PT. Gramedia Pustaka Umum.

Mubyarto 2009, Pengantar Ekonomi Pertanian, Jakarta : Edisi Ketiga, LP3S.

Mankiw, N. Gregory. 2013. Teori Makro Ekonomi, Edisi Kelima, Penerbit Erlangga, Jakarta

Najiyati dan Danarti.2014.Kopi Budidaya dan Penanganan Lepas Panen.Penerbar swadaya. Jakarta

Panggabean, Edy. 2011. Buku Pintar Kopi. Jakarta Selatan: PT Agro Media Pustaka hlm 124-132

Rahardjo, Pudji. 2012. Kopi Panduan Budidaya dan Pengolahan Kopi Arabika dan Robusta. Jakarta: Penebar Swadaya.

Soekartawi.2012. Prinsip Dasar Ekonomi Pertanian Teori dan Aplikasi.Jakarta Rajawali Pers.

Spillane, James J. 2010. Komoditi Kopi dan Peranannya Dalam Perekonomian Indonesia.Yogyakarta Kanisius.

Sudiyono, A. 2004. Pemasaran Pertanian. Edisi Kedua. UMM Press. Malang

Sugiyono. 2007. Metode Penelitian Kuantitatif Kualitatif dan R\&D. Bandung: Alfabeta.

Sukirno, Sadono. 2013. Makroekonomi : Teori Pengantar. Jakarta : PT. Raja Grafindo Persada.

Tim Karya Tani Mandiri. 2010. Pedoman Bertanam Kopi. Nuansa Aulia. Bandung.

Wei F, Tanokura M. 2015. Perubahan kimiawi dalam komponen biji kopi saat memanggang.J Healt and Disease. Doi.org/10.1016/B978(12): 409- 517. 